\title{
Highly Efficient Blue-Emitting Iridium(III) Carbene Complexes and Phosphorescent OLEDs**
}

\author{
Chiung-Fang Chang, Yi-Ming Cheng, Yun Chi,* Yuan-Chieh Chiu, Chao-Chen Lin, Gene- \\ Hsiang Lee, Pi-Tai Chou,* Chung-Chia Chen, Chih-Hao Chang, and Chung-Chih Wu*
}

Iridium(III)-based phosphorescent complexes have received considerable attention due to their possible applications in organic light-emitting diodes (OLEDs). ${ }^{[1]}$ Tuning of emission colors over the entire visible spectra has been achieved by ingenious modification of the cyclometalated and/or ancillary ligands. ${ }^{[2]}$ However, reports concerning the design and preparation of saturated blue or even near-UV phosphorescent materials are relatively rare. ${ }^{[3]}$ Increasing the emission energy gap means that there is a gradual decrease in the admixture of the ligand-centered $\pi \rightarrow \pi^{*}$ and metal-to-ligand charge-transfer (MLCT) transition, ${ }^{[4]}$ the net result of which is a reduction in the $\mathrm{T}_{1} \rightarrow \mathrm{S}_{0}$ transition probability and hence a low emission quantum efficiency (QE). Moreover, increasing the emission gap to blue raises the likelihood that thermal population of the higher lying $d d,{ }^{[5]} \operatorname{MLCT},{ }^{[6]} \mathrm{n} \pi *,{ }^{* a]}$ or even ligand-to-ligand charge-transfer states $(\mathrm{LLCT})^{[8]}$ could be invoked to account for the fast quenching at room temperature.

It has been reported recently that the use of high-fieldstrength ligands such as carbenes should result in an increase of the blue phosphorescent efficiency. ${ }^{[7]}$ As depicted in Scheme 1, an obvious way of achieving this goal is to treat $\mathrm{IrCl}_{3}$ with the benzoimidazole ligand 1-(4-fluorophenyl)-2,3dihydro-3-methyl- $1 H$-benzo $[d]$ imidazole $\left(\mathrm{H}_{2} \mathrm{fpmb}\right)$ to give the chloride-bridged dimer and then with the pyridyl triazole 4-tert-butyl-2-(5-(trifluoromethyl)-2H-1,2,4-triazol-3-yl)pyridine (bptzH) to afford the heteroleptic complex [(fpmb $)_{2}$ Ir(bptz)] (1). As cyclometalated carbene ligands theoretically

[*] C.-F. Chang, Dr. Y.-M. Cheng, Prof. Y. Chi, Y.-C. Chiu Department of Chemistry, National Tsing Hua University Hsinchu 300 (Taiwan)

Fax: (+ 886) 3572-0864

E-mail:ychi@mx.nthu.edu.tw

C.-C. Lin, Dr. G.-H. Lee, Prof. P.-T. Chou

Department of Chemistry, National Taiwan University

Taipei 106 (Taiwan)

Fax: (+886) 2-2369-5208

E-mail: chop@ntu.edu.tw

C.-C. Chen, C.-H. Chang, Prof. C.-C. Wu

Department of Electrical Engineering, Graduate Institute of Photonics and Optoelectronics and Graduate Institute of Electronics Engineering, National Taiwan University, Taipei 106 (Taiwan) Fax: (+886) 2-2367-1909

E-mail: chungwu@cc.ee.ntu.edu.tw

[**] This work was supported by the National Science Council and the Ministry of Economic Affairs of Taiwan. Organic light-emitting diodes (OLEDs).

9 Supporting information for this article is available on the WWW under http://www.angewandte.org or from the author.

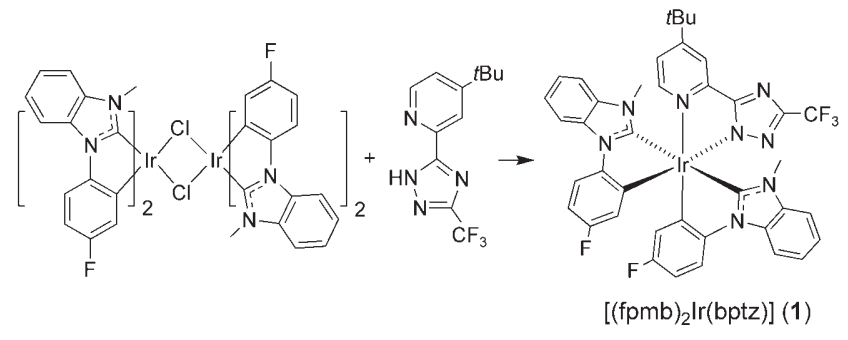

Scheme 1.

have a greater $\pi-\pi^{*}$ energy gap, the lowest one-electron excitation in $\mathbf{1}$ should occur solely on the triazolate chelates, which in the majority of cases possess a $\mathrm{T}_{1}-\mathrm{S}_{0}$ gap suitable for attaining blue phosphorescence. ${ }^{[9]}$ Unfortunately, complex $\mathbf{1}$ and its derivatives are poorly soluble in common solvents and have significantly lower luminescence efficiencies. These drawbacks have hampered the application of these complexes in the fabrication of high efficiency OLEDs.

Very recently, we have initiated an approach that involves interrupting the $\pi$-conjugation of the heterocyclic chelates on the heteroleptic $\operatorname{Ir}^{\mathrm{III}}$ scaffold by using a functionalized $N$ benzylpyrazole. This approach means that the $\pi$-electron crosstalk is effectively disrupted and causes the emission to occur at the other, more conjugated chromophore. This concept has proved to be successful for the synthesis of a series of phosphorescent $\operatorname{Ir}^{\mathrm{III}}$ complexes. ${ }^{[10]}$ Unfortunately, due to the twisting motion of the chelate ligands, which facilitates the nonradiative decay channels, these complexes do not serve as efficient true-blue phosphors but instead have been applied as the host materials for green phosphorescent OLEDs.

With the aim of continuing this effort, we report herein the use of a different functionalized benzyl carbene chelate ligand and its coordination to a different iridium source reagent, namely $\left[\mathrm{IrCl}_{3}(\mathrm{tht})_{3}\right]$ (tht $=$ tetrahydrothiophene), ${ }^{[1]}$ which is soluble in non-polar organic solvents. This change of reagents allows the preparation of blue-emitting $\operatorname{Ir}^{\mathrm{III}}$ complexes in a two-step synthetic manipulation involving: 1) generation of the cationic silver carbene intermediate, ${ }^{[12]}$ and 2) carbene transfer ${ }^{[13]}$ to the $\mathrm{Ir}^{\mathrm{III}}$ center and cyclometalation, followed by addition of the third, pyridyl azolate chelate ligand. ${ }^{[14]}$ The simplified reaction sequence leading to the isolation of $\left[(\mathrm{fbmb})_{2} \operatorname{Ir}(\mathrm{bptz})\right](\mathbf{2} ; \mathrm{fbmb}=1$-(4-fluorobenzyl)3-methylbenzimidazolium) and $\left[(\mathrm{dfbmb})_{2} \operatorname{Ir}(\mathrm{fptz})\right] \quad(\mathbf{3}$; $\mathrm{dfbmb}=1$-(2,4-difluorobenzyl)-3-methylbenzimidazolium $)$ is depicted in Scheme 2. It is believed that the use of aprotic xylenes as solvent reduces unwanted decomposition reactions and leads to an increase in the yield of isolated products to 


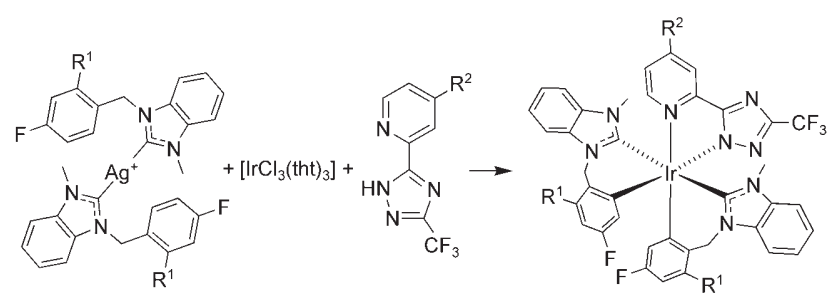

$\left[(\mathrm{fbmb})_{2} \mathrm{Ir}(\mathrm{bptz})\right] ; \mathrm{R}^{1}=\mathrm{H}, \mathrm{R}^{2}=\mathrm{tBu} ;(\mathbf{2})$ $\left[(\mathrm{dfbmb})_{2} \operatorname{Ir}(\mathrm{fptz})\right] ; \mathrm{R}^{1}=\mathrm{F}, \mathrm{R}^{2}=\mathrm{H} ;(3)$

Scheme 2.

around $50 \%$. Detailed synthetic procedures and characterization data for $\mathbf{2}$ and $\mathbf{3}$ are provided as Supporting Information.

Figure 1 shows the absorption and emission spectra of complexes 1-3 in degassed $\mathrm{CH}_{2} \mathrm{Cl}_{2}$. As supported by the frontier orbital analyses (see below), it is reasonable to assign

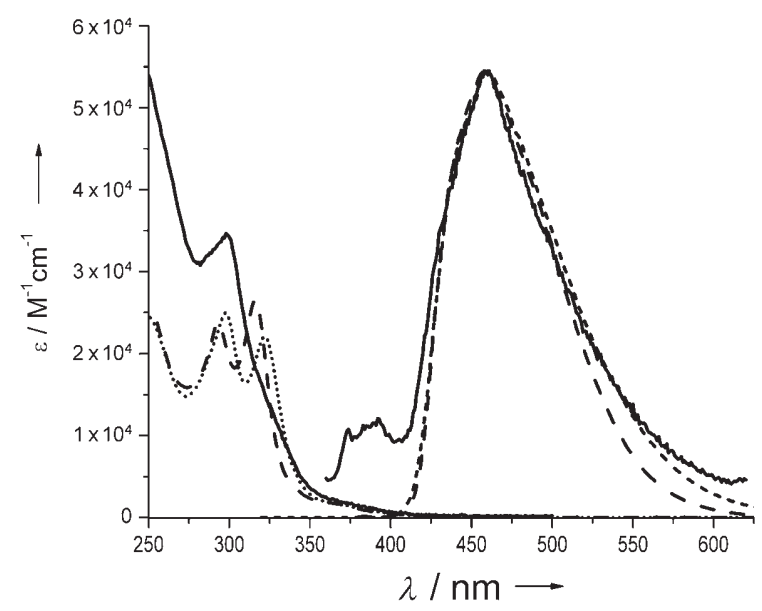

Figure 1. Absorption and luminescence spectra of $1(-), 2(---)$, and $3(--)$ in degassed $\mathrm{CH}_{2} \mathrm{Cl}_{2}$ at room temperature.

the absorption band at around $320 \mathrm{~nm}\left(\varepsilon \approx 2 \times 10^{4} \mathrm{M}^{-1} \mathrm{~cm}^{-1}\right)$ to overlap of the $\pi \rightarrow \pi^{*}$ transition of the triazolate chelate with the benzyl (carbene) to pyridyl (triazolate fragment) LLCT transition (the $S_{0} \rightarrow S_{1}$ transition). We have not assigned the higher electronic states of $\mathbf{1}-\mathbf{3}$ because their compositions are complicated due to the large molecular frameworks of these complexes, which are likely to render any assignments meaningless. Furthermore, iridium-enhanced spin-orbit coupling should result in a non-negligible absorption crosssection for the triplet transition, as indicated by the small absorption shoulder at around 360-400 nm.

Complexes 1-3 exhibit blue emission with maxima at 461, 460 , and $458 \mathrm{~nm}$, respectively. The phosphorescence intensity of $\mathbf{1}$ is rather weak, as indicated by its QE of only $5.0 \times 10^{-4}$ in fully degassed $\mathrm{CH}_{2} \mathrm{Cl}_{2}$. This, in combination with the observed lifetime $\left(\tau_{\text {obs }}\right)$ of $0.83 \mathrm{~ns}$, leads to a calculated radiative lifetime $\left(\tau_{\mathrm{r}}\right)$ of $1.67 \mu \mathrm{s}$. A short-wavelength (392 nm) emission is also observed for $\mathbf{1}$ (see Figure 1 and Table 1 ). This weak emission exhibits a system response limited lifetime $\left(\tau_{\text {obs }} \ll\right.$ $30 \mathrm{ps}$ and $\Phi_{\mathrm{f}}<10^{-4}$ ) and can reasonably be attributed to the
Table 1: Selected photophysical properties of $\mid \mathrm{r}^{\prime \prime \prime}$ complexes 1-3 in $\mathrm{CH}_{2} \mathrm{Cl}_{2}$.

\begin{tabular}{lllllll}
\hline & $\begin{array}{l}\text { UV/Vis }[n m] \\
\left(\varepsilon \times 10^{-3}\right)\end{array}$ & $\begin{array}{l}\mathrm{PL} \\
\lambda_{\max }[\mathrm{nm}]\end{array}$ & $\mathrm{QE}^{[\mathrm{a}]}$ & $\tau_{\text {obs }}[\mathrm{ns}]$ & $k_{\mathrm{r}}$ & $k_{n \mathrm{n}}$ \\
\hline 1 & $298(34.7), 318$ & 392,461 & $5.0 \times 10^{-4}$ & 0.83 & $6.0 \times 10^{5}$ & $1.2 \times 10^{9}$ \\
& $(17.4), 356(2.8)$ & & & & & \\
2 & $298(25.0), 322$ & 460 & 0.22 & 219 & $1.0 \times 10^{6}$ & $3.5 \times 10^{6}$ \\
& $(22.1), 363(1.8)$ & & & & & \\
3 & $293(23.7), 316$ & 458 & 0.73 & 378 & $1.9 \times 10^{6}$ & $7.0 \times 10^{5}$ \\
& $(26.5), 363(1.8)$ & & & & & \\
\hline
\end{tabular}

[a] With respect to quinine sulfate, which has an emission yield $\Phi$ of approximately $0.54 \pm 0.2$ in $1.0 \mathrm{~N}$ sulfuric acid solution. ${ }^{[18]}$

fluorescence, which is resolvable due to the similarly weak phosphorescence. Conversely, the QEs of 0.22 and 0.73 for 2 and $\mathbf{3}$, respectively, are much higher than that of $\mathbf{1}$. The observed lifetimes of 0.22 and $0.38 \mu$ s for these complexes lead to radiative lifetimes of 1.0 and $0.5 \mu$ s for $\mathbf{2}$ and $\mathbf{3}$, respectively. The radiative lifetimes of all complexes confirm their phosphorescent nature. It is notable that the large difference in QE between $\mathbf{1}$ and $\mathbf{2}$ (or 3) is due to the distinctively different nonradiative decay rate constants, $k_{\mathrm{nr}}$, of $1.2 \times 10^{9}, 3.5 \times 10^{6}$, and $7.0 \times 10^{5} \mathrm{~s}^{-1}$ for $\mathbf{1}-\mathbf{3}$, respectively.

A time-dependent density functional theory (TD-DFT) approach (see the Supporting Information) was next applied to gain an insight into the structure/photophysics relationship. Geometry optimization of the lowest triplet excited states of complexes 1-3 was performed to elucidate the nature of the emissive state. Figure 2 depicts the frontier orbitals of $\mathbf{3}$ that
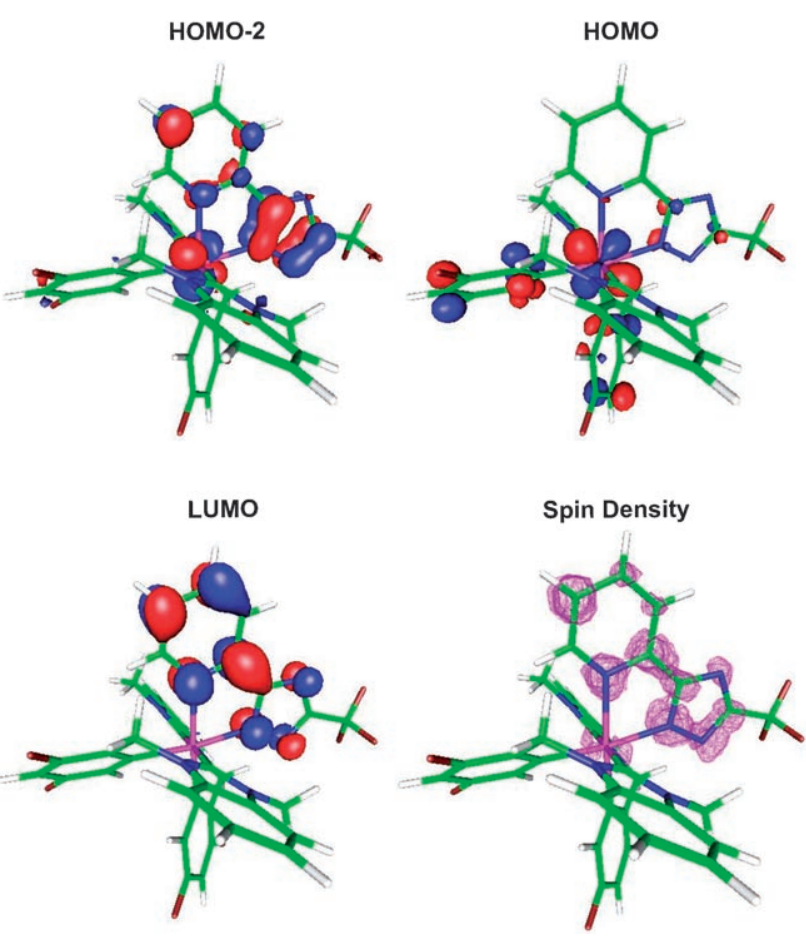

Figure 2. Frontier orbitals mainly involved in the low-lying $\mathrm{S}_{0} \rightarrow \mathrm{T}_{1}$ transitions of $\mathbf{3}$ based on the structurally optimized geometry in the lowest-lying triplet state and the spin density of the triplet electronic configuration. The orbitals for complexes $\mathbf{1}$ and $\mathbf{2}$ are depicted in Figure $\mathbf{S} 6$ in the Supporting Information. 
are mainly involved in the low-lying $\mathrm{S}_{0} \rightarrow \mathrm{T}_{1}$ transitions along with the spin density contour for the triplet electronic state. The orbital descriptions and the energy gaps for all three complexes are listed in Table 2 . The $\mathrm{T}_{1}$ states of the lower-

Supporting Information, the average bite angle of the carbene chelate ligands in $\mathbf{1}\left(78.9^{\circ}\right)$ is much smaller than that of $\mathbf{2}$ $\left(86.6^{\circ}\right)$ despite their $\mathrm{Ir}-\mathrm{C}$ distances being almost identical within experimental error. A similar difference is also found between $\mathbf{1}$ and $\mathbf{3}$. These results allow us to propose a large internal strain upon incorporating the fpmb carbene chelate into $\mathbf{1}$ relative to that of fbmb (dfbmb) in 2 (3). Certain vibrational motions, such as those modes associated with carbene-chelate ring breathing, Ir-C stretching, etc., may significantly weaken the metal-ligand bond strength. The corresponding potential energy surface (PES) might therefore become shallow enough to intersect with the PES of the ground state. ${ }^{[15]}$ Such a conical type of PES intersection may allow dominant radiationless deactivation which, in a qualitative

lying transitions of $\mathbf{1}-\mathbf{3}$ share the same pattern (HOMO-2 $\rightarrow$ LUMO and HOMO $\rightarrow$ LUMO) consisting of the $\pi \rightarrow \pi^{*}$ transition on the pyridyl azolate, mixed with LLCT (fluorophenyl to the azolate fragment) and MLCT (metal to pyridyl azolate), despite the different ligand configurations in these complexes (conjugated fpmb versus nonconjugated dfbmb (or fbmb)). The validity of the TD-DFT result can readily be seen from the wavelengths calculated for the $T_{1} \rightarrow S_{0}$ transitions (491, 480, and $463 \mathrm{~nm}$ for $\mathbf{1}-\mathbf{3}$, respectively), which are in good agreement with the experimentally observed phosphorescence. A careful analysis of the character of each transition highlights a trend of increasing MLCT contributions from $\mathbf{1}$ $\left(\mathrm{T}_{1}: 22 \%\right)$ to $\mathbf{2}(30 \%)$ and $\mathbf{3}(32 \%$; Table 2$)$. Since an increase of MLCT character enhances spin-orbit coupling and hence the transition probability, this observation correlates well with the trend of the radiative decay rate constant being in the order $\mathbf{1}<\mathbf{2}<\mathbf{3}$ (see Table 1). Nevertheless, the approximate threefold difference between $\mathbf{1}$ and $\mathbf{3}$ is not sufficient to account for the large difference in emission QE, in other words the large discrepancy in view of radiationless deactivation. A careful examination of the frontier orbitals involved in each transition for complexes $\mathbf{1 - 3}$ shows that the calculated $\mathrm{S}_{0} \rightarrow \mathrm{T}_{n}(1 \leq n \leq 10)$ transitions have no contribution from the metal-centered $\mathrm{d}_{\pi} \mathrm{d}_{\sigma^{*}}$ and/or ligand-to-metal $\mathrm{d}_{\mathrm{\sigma}^{*}}$ states. Instead, the unoccupied orbitals with $d_{\sigma^{*}}$ character are ascribed to the LUMO+11 for $\mathbf{1}$ (see the Supporting Information) and even higher for $\mathbf{2}$ and $\mathbf{3}$. In the case of $\mathbf{1}$, the $d_{\pi} d_{\sigma^{*}}$ state is more than $3 \mathrm{eV}$ higher in energy than the $T_{1}$ state and is therefore inaccessible at room temperature. Orbital analyses further indicate that there is no contribution from any atoms possessing nonbonding electrons to the lowerlying triplet excited-states. These results mean that the generally adopted mechanism whereby the ${ }^{3} d_{\pi} d_{\sigma^{*}}\left(\right.$ or $\left.{ }^{3} \pi d_{\sigma^{*}}\right)$ and/or $n \pi^{*}$ states are responsible for the lack of roomtemperature emission for $\mathbf{1}$ is not operative here. ${ }^{[7 a]}$

The X-ray structural data reveal significant differences between $\mathbf{1}$ and $\mathbf{2}$ (or $\mathbf{3}$ ). As can be seen in Figures S1-S3 in the manner, rationalizes the rather weak emission observed for $\mathbf{1}$.

Complex $\mathbf{3}$ was used as the dopant for fabrication of blue phosphorescent OLEDs due to its superior emission quantum yield. The device configurations and materials used (see Figure $\mathrm{S} 4$ in the Supporting Information) were ITO/ $\alpha$-NPD $(30 \mathrm{~nm}) / \mathrm{TCTA}(20 \mathrm{~nm}) / \mathrm{CzSi}(3 \mathrm{~nm}) / \mathrm{CzSi}$ doped with $6 \mathrm{wt}$ \% of $3(25 \mathrm{~nm}) / \mathrm{UGH} 2$ doped with 6 wt. $\%$ of $\mathbf{3}(3 \mathrm{~nm}) / \mathrm{UGH} 2$ $(2 \mathrm{~nm}) / \mathrm{BCP}(50 \mathrm{~nm}) / \mathrm{Cs}_{2} \mathrm{CO}_{3}(2 \mathrm{~nm}) / \mathrm{Al}(150 \mathrm{~nm})$. Figures $3 \mathrm{a}$ and $3 \mathrm{~b}$ show the electroluminescence (EL) spectrum and the corresponding CIE color coordinates, while Figures $3 \mathrm{c}$ and $3 \mathrm{~d}$ depict the current-voltage-luminance $(I-V-L)$ characteristics and the EL efficiencies of the device. The EL spectrum, which exhibits two distinct emission peaks, one at $434 \mathrm{~nm}$ and the other at $460 \mathrm{~nm}$, is slightly different from the solution PL spectrum depicted in Figure 1. The 1931 Commission Internationale de L'Eclairage $(x, y)$ coordinates $\left(\mathrm{CIE}_{x, y}\right)$ calculated
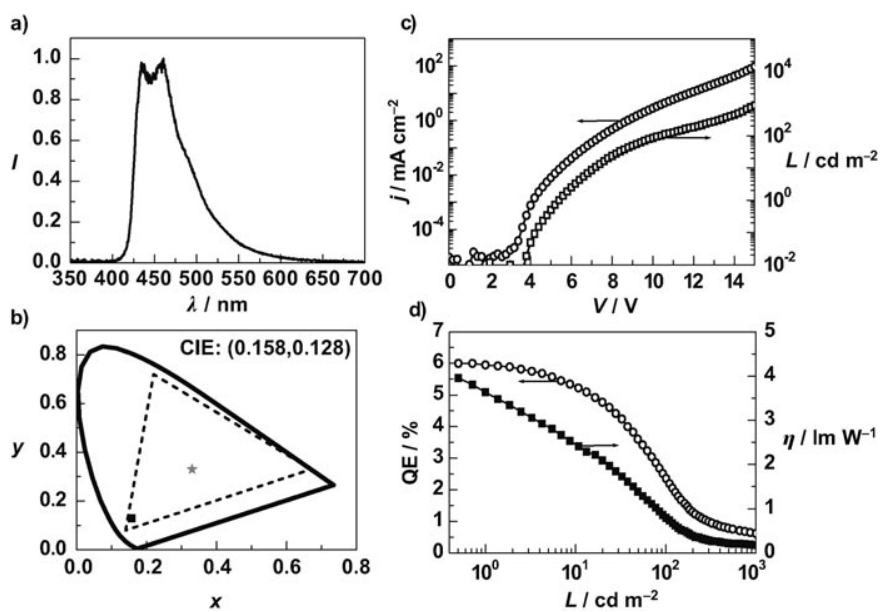

Figure 3. a) EL spectrum, b) CIE chromaticity coordinates, c) I-V-L characteristics ( $j=$ current density, $L=$ brightness), and d) external quantum efficiency and power efficiency $(\eta)$ versus brightness $L$ for the device containing $\mathbf{3}$ as the dopant. 
from the EL spectrum $(0.158,0.128)$ are blue-shifted with respect to the solution PL (with CIE coordinates of 0.149 , 0.154) or PL of a vacuum-deposited, 3-doped UGH2 thin film $(0.168,0.143)$. This difference is presumably associated with the optical effects of the device. Moreover, this device exhibits a low turn-on voltage of around $4 \mathrm{~V}$, a peak external quantum efficiency of up to $6.0 \%$ photons per electron, a peak luminance efficiency of $6.3 \mathrm{~cd} \mathrm{~A}^{-1}$, and a peak power efficiency of $4.0 \mathrm{~lm} \mathrm{~W}^{-1}$. At the practical brightness of $100 \mathrm{~cd} \mathrm{~m}^{-2}$, the external quantum efficiency, luminance efficiency, and power efficiency drop to about $2.7 \%, 3.0 \mathrm{~cd} \mathrm{~A}^{-1}$, and $0.9 \mathrm{~lm} \mathrm{~W} \mathrm{~m}^{-1}$, respectively. These efficiency roll-offs are to be expected for phosphorescent OLEDs at higher current densities. ${ }^{[16]}$ Nevertheless, the CIE coordinates of the present device are much better than for other devices fabricated from other well-known blue phosphorescent dopants (FIrpic, Fir6, FIrtaz, FIrN4) ${ }^{[17]}$ which display $\mathrm{CIE}_{y} \geq 0.2$ and $\mathrm{CIE}_{x+y} \geq 0.4$. As a result, the chromaticity of $\mathbf{3}\left(\mathrm{CIE}_{x+y} \leq 0.3\right)$ may strongly stimulate the further development of efficient deep-blue phosphors for display or lighting applications.

In conclusion, a nonconjugated benzyl carbene chelate ligand can form blue-emitting Ir $^{\mathrm{III}}$ metal complexes and a prototype phosphorescent OLED with unprecedented CIE coordinates $(0.16,0.13)$ has been fabricated from complex 3 . Extensive chemical modifications following this strategy are thus feasible and could lead to a new chapter in the story of highly efficient blue phosphorescent OLEDs.

Received: February 14, 2008

Published online: May 6, 2008

Keywords: carbene ligands - density functional calculations . iridium · luminescence $\cdot \mathrm{N}$ ligands

[1] a) R. C. Evans, P. Douglas, C. J. Winscom, Coord. Chem. Rev. 2006, 250, 2093; b) H. Yersin, Top. Curr. Chem. 2004, 241, 1; c) S.-W. Lai, C.-M. Che, Top. Curr. Chem. 2004, 241, 27; d) M. K. Nazeeruddin, M. Grätzel, Struct. Bonding (Berlin) 2007, 123 113; e) P.-T. Chou, Y. Chi, Chem. Eur. J. 2007, 13, 380; f) P.-T. Chou, Y. Chi, Eur. J. Inorg. Chem. 2006, 3319.

[2] a) A. B. Tamayo, S. Garon, T. Sajoto, P. I. Djurovich, I. M. Tsyba, R. Bau, M. E. Thompson, Inorg. Chem. 2005, 44, 8723; b) F.-M Hwang, H.-Y. Chen, P.-S. Chen, C.-S. Liu, Y. Chi, C.-F. Shu, F.-I. Wu, P.-T. Chou, S.-M. Peng, G.-H. Lee, Inorg. Chem. 2005, 44, 1344 ; c) T. Matsushita, T. Asada, S. Koseki, J. Phys. Chem. C 2007, 111, 6897; d) G. Zhou, C.-L. Ho, W.-Y. Wong, Q. Wang, D. Ma, L. Wang, Z. Lin, T. B. Marder, A. Beeby, Adv. Funct. Mater. 2008, 18, 499.

[3] a) M. K. Nazeeruddin, R. Humphry-Baker, D. Berner, S. Rivier, L. Zuppiroli, M. Graetzel, J. Am. Chem. Soc. 2003, 125, 8790; b) P. Coppo, E. A. Plummer, L. De Cola, Chem. Commun. 2004, 1774 ; c) E. Orselli, G. S. Kottas, A. E. Konradsson, P. Coppo, R. Fröhlich, L. De Cola, A. van Dijken, M. Büchel, H. Börner, Inorg. Chem. 2007, 46, 11082; d) S.-C. Lo, C. P. Shipley, R. N. Bera, R. E. Harding, A. R. Cowley, P. L. Burn, I. D. W. Samuel, Chem. Mater. 2006, 18, 5119; e) C.-H. Yang, S.-W. Li, Y. Chi,
Y.-M. Cheng, Y.-S. Yeh, P.-T. Chou, G.-H. Lee, C.-H. Wang, C.-F. Shu, Inorg. Chem. 2005, 44, 7770; f) Y. You, S. H. Kim, H. K. Jung, S. Y. Park, Macromolecules 2006, 39, 349; g) P.-I. Shih, C.-H. Chien, C.-Y. Chuang, C.-F. Shu, C.-H. Yang, J.-H. Chen, Y. Chi, J. Mater. Chem. 2007, 17, 1692; h) S. Takizawa, J. Nishida, T. Tsuzuki, S. Tokito, Y. Yamashita, Inorg. Chem. 2007, 46, 4308; i) L. Chen, H. You, C. Yang, D. Ma, J. Qin, Chem. Commun. 2007, 1352; j) D. DiCenso, S. Fantacci, F. De Angelis, C. Klein, N. Evans, K. Kalyanasundaram, H. J. Bolink, M. Grätzel, M. K. Nazeeruddin, Inorg. Chem. 2008, 47, 980.

[4] C.-H. Yang, Y.-M. Cheng, Y. Chi, C.-J. Hsu, F.-C. Fang, K.-T. Wong, P.-T. Chou, C.-H. Chang, M.-H. Tsai, C.-C. Wu, Angew. Chem. 2007, 119, 2470; Angew. Chem. Int. Ed. 2007, 46, 2418.

[5] a) G. H. Allen, R. P. White, D. P. Rillema, T. J. Meyer, J. Am. Chem. Soc. 1984, 106, 2613; b) H. Miki, M. Shimada, T. Azumi, J. A. Brozik, G. A. Crosby, J. Phys. Chem. 1993, 97, 11175.

[6] R. S. Lumpkin, E. M. Kober, L. A. Worl, Z. Murtaza, T. J. Meyer, J. Phys. Chem. 1990, 94, 239.

[7] a) T. Sajoto, P. I. Djurovich, A. Tamayo, M. Yousufuddin, R. Bau, M. E. Thompson, R. J. Holmes, S. R. Forrest, Inorg. Chem. 2005, 44, 7992; b) J. Li, P. I. Djurovich, B. D. Alleyne, M. Yousufuddin, N. N. Ho, J. C. Thomas, J. C. Peters, R. Bau, M. E. Thompson, Inorg. Chem. 2005, 44, 1713.

[8] Y.-S. Yeh, Y.-M. Cheng, P.-T. Chou, G.-H. Lee, C.-H. Yang, Y. Chi, C.-F. Shu, C.-H. Wang, ChemPhysChem 2006, 7, 2294.

[9] a) C.-J. Chang, C.-H. Yang, K. Chen, Y. Chi, C.-F. Shu, M.-L. Ho, Y.-S. Yeh, P.-T. Chou, Dalton Trans. 2007, 1881; b) I. Avilov, P. Minoofar, J. Cornil, L. De Cola, J. Am. Chem. Soc. 2007, 129, 8247.

[10] Y.-H. Song, Y.-C. Chiu, Y. Chi, Y.-M. Cheng, C.-H. Lai, P.-T. Chou, K.-T. Wong, M.-H. Tsai, C.-C. Wu, Chem. Eur. J. 2008, DOI: $10.1002 /$ chem.200800050.

[11] K. D. John, K. V. Salazar, B. L. Scott, R. T. Baker, A. P. Sattelberger, Organometallics 2001, 20, 296.

[12] a) S. Burling, M. F. Mahon, S. P. Reade, M. K. Whittlesey, Organometallics 2006, 25, 3761; b) P. L. Chiu, C. Y. Chen, C.-C. Lee, M.-H. Hsieh, C.-H. Chuang, H. M. Lee, Inorg. Chem. 2006, $45,2520$.

[13] a) N. Stylianides, A. A. Danopoulos, N. Tsoureas, J. Organomet. Chem. 2005, 690, 5948; b) V. J. Catalano, A. O. Etogo, Inorg. Chem. 2007, 46, 5608.

[14] Y.-H. Song, S.-J. Yeh, C.-T. Chen, Y. Chi, C.-S. Liu, J.-K. Yu, Y.H. Hu, P.-T. Chou, S.-M. Peng, G.-H. Lee, Adv. Funct. Mater. 2004, 14, 1221.

[15] a) J.-K. Yu, Y.-H. Hu, Y.-M. Cheng, P.-T. Chou, S.-M. Peng, G.H. Lee, A. J. Carty, Y.-L. Tung, S.-W. Lee, Y. Chi, C.-S. Liu, Chem. Eur. J. 2004, 10, 6255; b) Y. Chi, P.-T. Chou, Chem. Soc. Rev. 2007, 36, 1421.

[16] a) M. Cocchi, D. Virgili, V. Fattori, D. L. Rochester, J. A. G. Williams, Adv. Funct. Mater. 2007, 17, 285; b) S. Reineke, G. Schwartz, K. Walzer, K. Leo, Appl. Phys. Lett. 2007, 91, 123508.

[17] a) R. J. Holmes, S. R. Forrest, Y.-J. Tung, R. C. Kwong, J. J. Brown, S. Garon, M. E. Thompson, Appl. Phys. Lett. 2003, 82, 2422; b) R. J. Holmes, B. W. D'Andrade, S. R. Forrest, X. Ren, J. Li, M. E. Thompson, Appl. Phys. Lett. 2003, 83, 3818; c) S.-J. Yeh, W.-C. Wu, C.-T. Chen, Y.-H. Song, Y. Chi, M.-H. Ho, S.-F. Hsu, C.-H. Chen, Adv. Mater. 2005, 17, 285; d) M.-F. Wu, S.-J. Yeh, C.-T. Chen, H. Murayama, T. Tsuboi, W.-S. Li, I. Chao, S.-W. Liu, J.-K. Wang, Adv. Funct. Mater. 2007, 17, 1887.

[18] J. N. Crosby, G. A. Dernas, J. Phys. Chem. 1971, 75, 991. 